\title{
An Electrical Wave Height Measurement at Spatial Multipoint Locations in Liquid Dampers for Structural Vibration Mitigation
}

\author{
Junhee Kim, Seok-Jung Jang, and Kyung-Won Min \\ Department of Architectural Engineering, Dankook University, Jukjeon-dong, Suji-gu, Yongin-si, \\ Gyeonggi-do 448-701, Republic of Korea \\ Correspondence should be addressed to Kyung-Won Min; 11700340@dankook.ac.kr
}

Received 29 February 2016; Accepted 11 July 2016

Academic Editor: Ki Y. Koo

Copyright (C) 2016 Junhee Kim et al. This is an open access article distributed under the Creative Commons Attribution License, which permits unrestricted use, distribution, and reproduction in any medium, provided the original work is properly cited.

Liquid dampers such as tuned liquid column dampers and tuned liquid dampers have been adopted to ensure serviceability of a vibratory building subjected to wind. In order to maximize efficiency of the vibration suppression, tuning frequency of the liquid dampers is supposed to be set to the first natural frequency of the building. Therefore, experimental evaluation of the natural frequency of liquid dampers is a primal factory task prior to their installation at the building. In this study, a novel liquid height measurement system based on variable resistance in an electric field is developed for observation of vertical motion of the liquid dampers. The proposed system can simultaneously measure the liquid height of multipoint locations in the electric field. In the experimental phase, natural frequency of the liquid dampers is experimentally evaluated utilizing the developed system. The performance of the proposed system is verified by comparison with the capacitive type wavemeter.

\section{Introduction}

Vibration mitigation of buildings has been emphasized to meet serviceability requirements for residents at high-rise buildings sensitive to wind and earthquakes loads [1]. One of the pervasive strategies widely applied to attenuate structural vibration is installation of a passive energy-absorbing device on the top floor of a building. A tuned mass damper (TMD) is a mechanical device consisting of a spring mass system. The secondary mass is a small fraction of the entire mass of the primary structure and generates a reaction force induced from an oscillating motion of the mass [2]. On the other hand, liquid dampers are similar to the TMD except that they take advantage of oscillating liquid motion in the gravity field [3, 4]. The tuning frequency ratio, which is a critical parameter in the design of the liquid dampers, can be easily controlled by length of the liquid container [5-7]. Two different configurations of the liquid dampers have been investigated: the tuned liquid column damper (TLCD) and tuned liquid damper (TLD) utilize energy dissipating liquid motions of oscillation in U-shaped narrow tubes and wave braking/sloshing in free liquid surface, respectively $[8,9]$.
The design task of the U-shaped TLCD is to identify its natural frequency and then to tune it to the fundamental natural frequency of a building structure. The natural frequency of the TLCD depends on liquid portion in horizontal column which participates in the tuned reciprocating motion $[10,11]$. The liquid surface remains fairly flat during oscillating because the TLCD utilized the whole liquid in the U-shaped tube. Thus, analysis and design of the TLCD are rather straightforward. On the other hand, researches regarding the TLD are complicated because the liquid motion in the TLD is highly nonlinear. A majority of researches focus on exploring a better understanding of the liquid's motion in a tank through physical experimentation. In order to analyze accurately the movement of liquid in the TLD, a multipoint measurement is strongly needed to determine sloshing modes of the TLD, since the first several modes are predominant in the TLD unlike the TLCD where the first oscillating mode is governed [12].

To date, capacitive wavemeters have been dominantly used for liquid height measurements. However, a number of intrinsic disadvantages have been constantly addressed: laborious installation, a loss of accuracy due to interference 


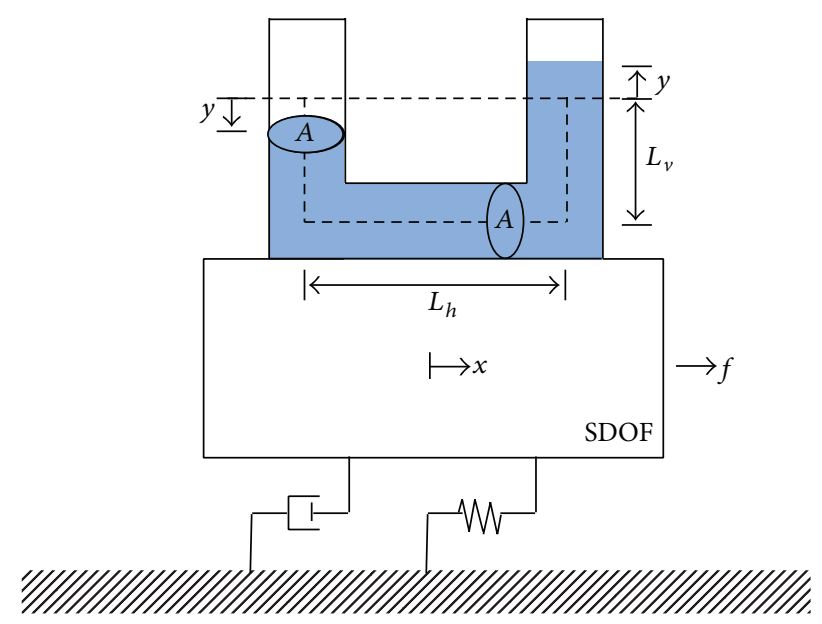

Figure 1: Modeling of a SDOF structure with a TLCD.

from the liquid medium, for example, parasitic capacitance, and difficulty of measurements at closely adjacent points. While great advances have been made in numerical and analytical studies of dynamic behaviors of the TLCD [1316] and practical design guidelines and formulas $[9,17-$ 19], comparatively less research has been conducted on development of novel measurement strategies and studies on further characterization of the liquid dampers based on experimentally measured data.

In this study, a novel, high precision, and cost-effective variable voltage sensing system is developed for dynamic wave height measurement of the liquid dampers of both the TLD and TLCD to identify natural frequencies and corresponding modes. The variable voltage sensing principle is introduced with basic electric circuit theory. A practical methodology of experimental estimation of dynamic characteristics is presented based on both dynamic equations of natural frequency derived and experimental data measured. Finally, a series of experimental investigations are conducted for the verification of the variable voltage sensing system and for showcasing the methodology of natural frequency of the TLD and TLCD.

\section{Analytical Natural Frequency of a Liquid Mass Damper}

2.1. Formulation of Natural Frequency of TLCDs. A simplified model of the TLCD built on a primary structure is shown in Figure 1. The TLCD is composed of a U-shaped liquid tank of a combination of horizontal and vertical poles and the liquid is considered homogeneous, irrotational, and incompressible. The cross-sectional area of the TLCD is denoted as A. The horizontal and vertical column lengths are defined as $L_{h}$ and $L_{v}$, respectively. Two boundary conditions are imposed at the liquid free surface: the first is the kinematic boundary condition, which states that a liquid particle on the free surface at all the time will always be on the free surface, and the second one is dynamic boundary condition, which specifies that the pressure on the free surface is zero.

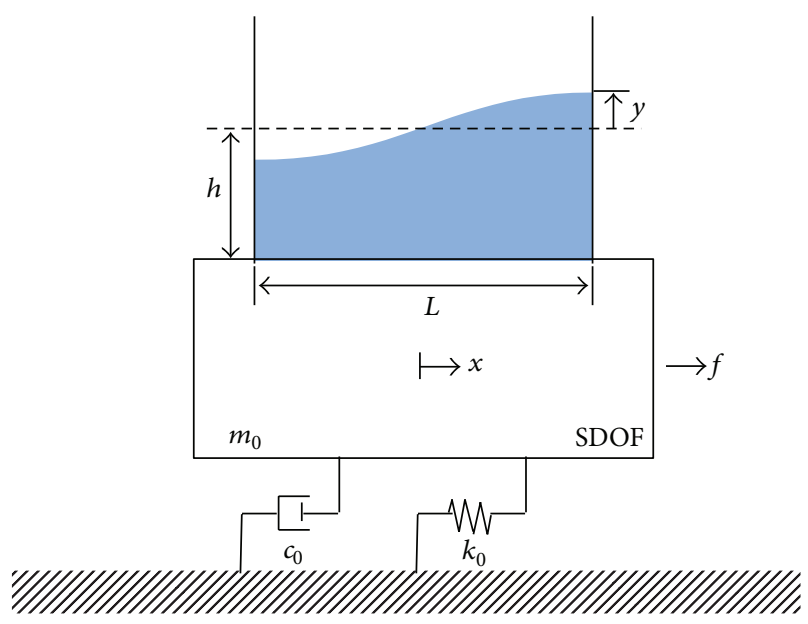

FIgURE 2: Modeling of a SDOF structure with a TLD.

Three assumptions are made to derive the equation of motion: (i) the sloshing behavior on the liquid surface is negligible; (ii) the flow is incompressible; (iii) the dimension of the column cross section is much smaller than the horizontal length of a TLCD. The dynamic equation of the oscillating liquid in the TLCD subjected to lateral excitation of the primary structure is [20]

$$
\rho A\left(L_{h}+2 L_{v}\right) \ddot{y}+\frac{1}{2} \rho A \eta|\dot{y}| \dot{y}+2 \rho A g y=-\rho A L_{h} \ddot{x},
$$

where the liquid density, head loss coefficient, and velocity of liquid in the TLCD are represented by $\rho, \eta$, and $\dot{y}$, respectively. The acceleration of gravity is expressed by $g$. From mass and stiffness terms in (1), the natural frequency of liquid motion in the TLCD is calculated as

$$
f_{n}=\frac{1}{2 \pi} \sqrt{\frac{2 g}{L_{h}+2 L_{v}}} .
$$

The liquid surface in the TLCD remains nearly flat during sloshing, because the portion that does not participate in the sloshing of the liquid is removed in the TLCD. Therefore, the whole liquid reciprocates in the TLCD and the natural frequency also appears only as primary mode, as (2).

2.2. Derivation of Natural Frequency of TLDs. A rigid rectangular TLD shown in Figure 2 has the length $L$ and the liquid depth at rest $h$. The TLD is subjected to a lateral excitation, $x$, the movement of the primary structure. The equation of liquid motion in the container can be described in the free surface motion assuming the shallow water wave theory.

According to the shallow water wave theory [20], in the TLD with the length ratio, $h / L$, ranging from 0.04 to 0.5 , the liquid level sloshes within the container and the fundamental frequencies of linear sloshing are

$$
f_{n}=\frac{1}{2 \pi} \sqrt{\frac{(2 n-1) \pi g}{L} \tanh \left\{\frac{(2 n-1) \pi h}{L}\right\}},
$$

$$
n=1,2, \ldots
$$




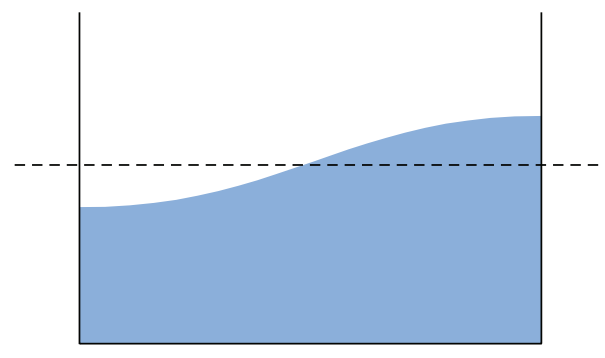

(a)

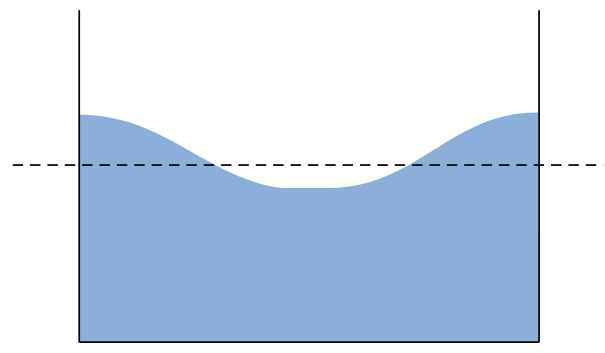

(b)

FIGURE 3: Sloshing modes of the TLD: (a) the first mode; (b) the second mode.

Unlike the TLCD, the TLD behaves nonlinearly due to the fluid motion inside the liquid tank. As a result, the natural frequency is dependent on the amplitude of the excitation force. In the content, the simplified physical models often fail to represent sloshing phenomena and thus the importance of experiments is accentuated especially to determine the exact natural frequency. In this study, the sloshing modes of the TLD are accurately analyzed as shown in Figure 3 by virtue of multipoint measurements proposed.

\section{Development of Liquid Height Measurement in the Electric Field}

3.1. Two-Point and Four-Point Resistivity Measurements. Properties of the bulk material used for fabrication of transistors and other semiconductor devices can be estimated by measurement of resistance [21]. In order to measure material resistance, two-point and four-point measurement systems have been developed using constant current method. Figure 4 represents a two-point resistance test configuration. The material under the test has the resistance, $R_{d u t}$, itself but with three parasitic resistances: (1) the probe has the probe resistance, $R_{p}$; (2) the contact resistance, $R_{c p}$, exists between the probe and the material under; (3) there is the spreading resistance, $R_{s p}$, when the current runs from the probe to the material.

Using Ohm's law, the total resistance is determined as

$$
V=I\left(R_{d u t}+2 R_{p}+2 R_{c p}+2 R_{s p}\right),
$$

where $V$ is the voltage reading from the voltmeter and $I$ is the current carried by the two current-carrying probes.

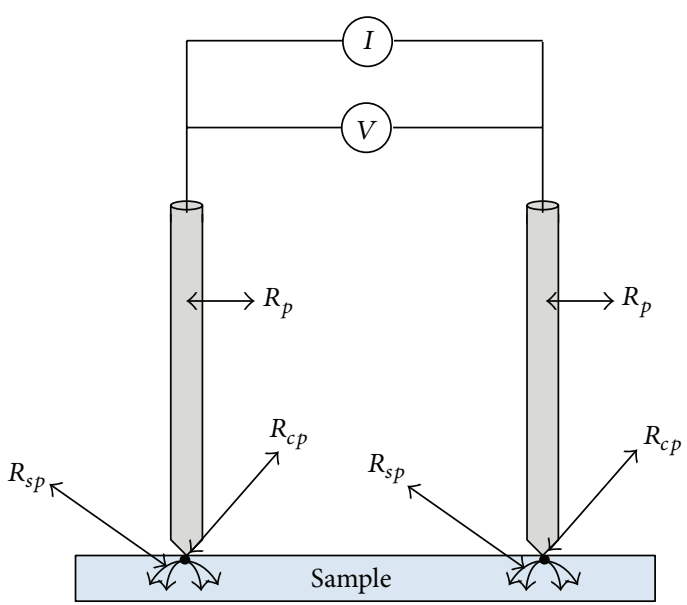

(a)

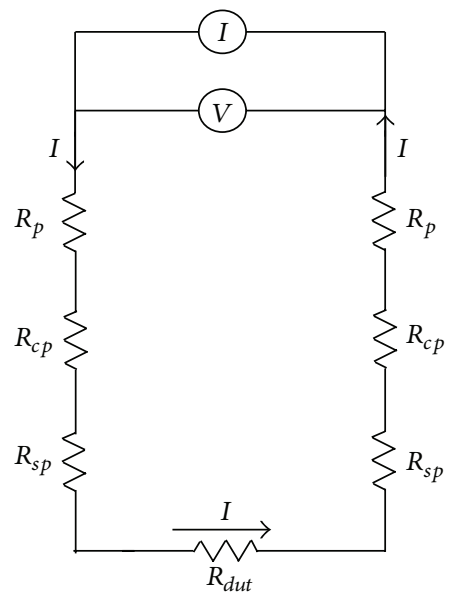

(b)

FIGURE 4: Two-point measurement system: (a) two-probe meter; (b) corresponding circuit diagram.

Because the current causes voltage drop across the parasitic resistances, the voltage measured by the meter is not exactly the same as the voltage directly across the material resistance and thus considerable error can result. The parasitic resistances range typically from $10 \mathrm{~m} \Omega$ to $1 \Omega$ [21] and thus are not negligible in case of low resistance measurements.

Due to the limitations of the two-point method, the fourpoint measurement system is used for the low resistance measurements in order to reduce the effect of parasitic resistances [22]. The measurement of the device resistance under test by using four-point probes is shown in Figure 5 where two probes carry the current and the other two probes measure the voltage. Each probe has the aforementioned parasitic resistances. However, these parasitic resistances can be neglected for the two voltage probes, because the voltage is measured with a high impedance voltmeter. The voltmeter draws very little current, typically less then $100 \mathrm{pA}$ [23]. By using the 4-point method, the resistance is determined as

$$
V=(I-i) R_{d u t}-i\left(2 R_{p}+2 R_{c p}+2 R_{s p}\right) \cong I R_{d u t} .
$$




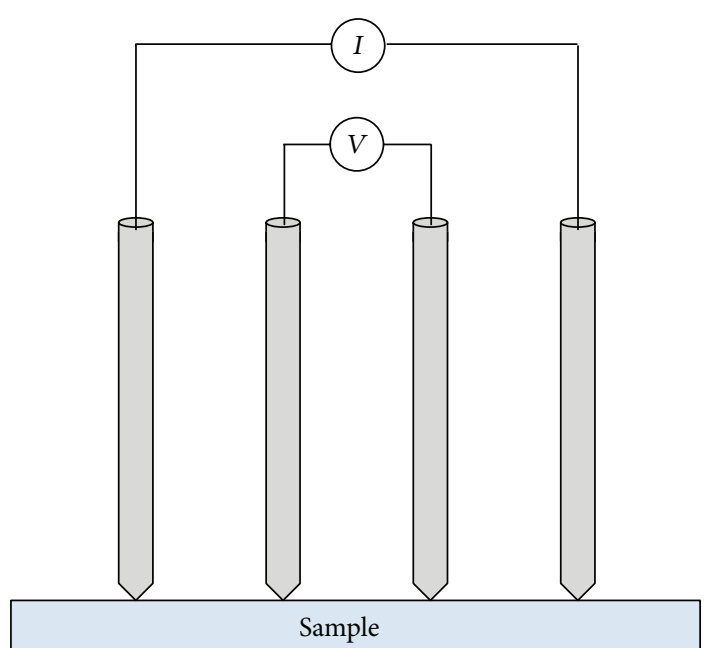

(a)

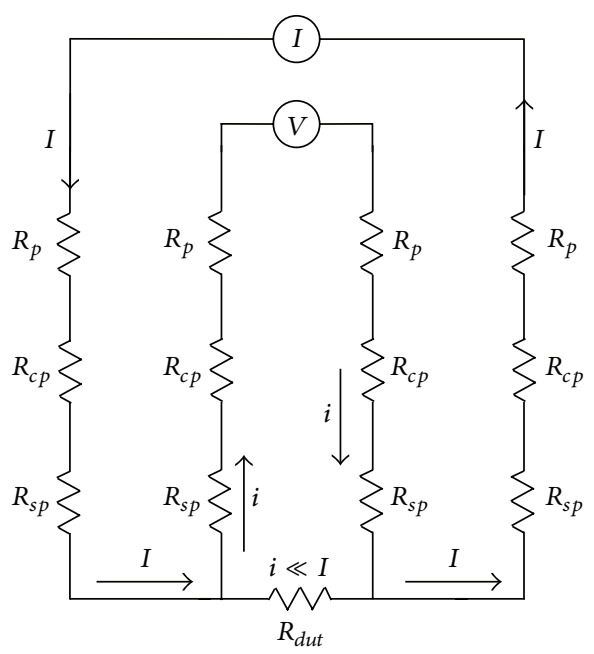

(b)

FIGURE 5: Four-point measurement system: (a) four-probe meter; (b) corresponding circuit diagram.

Assuming a very large resistance of the material compared to the parasitic resistances, resistance is measured from both two-point and four-point measurement systems [21, 22] as

$$
V=F \cdot I \cdot R_{d u t},
$$

where $F$ is the product of three separate correction factors and determined as

$$
F=F_{1} \cdot F_{2} \cdot F_{3}
$$

where $F_{1}$ is the correction coefficient of the sample size for the sample, $F_{2}$ is the correction coefficient of the thickness of the sample to the probe spacing, and $F_{3}$ is the correction coefficient of temperature factor. The correction coefficients are determined typically through a priori test [23-25].

3.2. Formulation of Liquid Height Measurements. Based on the results of resistivity measurement, that is, (6), this study extends its applications to liquid height measurements in the liquid dampers by utilizing water column as conductive media to measure the resistance (Figure 6). In order to increase the conductivity of water, electrically ionized water from dissolving small amount of electrolytes into tap water is utilized. A power supplier is connected to two electrodes in the TLCD controlling constant current flow regardless of wave height change of the water column. A voltmeter shears the lines to measure voltage drop between the electrodes.

The resistance is proportional to the conductor length, $L$, but inversely proportional to the cross-sectional area, $S$. The cross-sectional area is represented by multiplication of the effective width of the electric field, $W$, and the height, $H$. Considering a proportionality constant in the resistance termed resistivity, $\rho_{e}$, Ohm's law is written as

$$
V=F I \rho_{e} \frac{L}{W H} .
$$

Since the current, resistivity, distance of the electrodes, correction factor, and width of the constant electric field remain constant regardless of varying liquid level, voltage change is related only to liquid level. Taking all the constant parameters in (8) as a term of $\beta$ leads to

$$
V=\frac{\beta}{H}
$$

While the two-point measurement system is applied to the TLCD, the four-point measurement system is deployed in the TLD for multipoint measurement (Figure 7) where $n$ voltmeters are interfaced in a row. Similar to the case of connection of a voltmeter, that is, (9), each of the voltage drops is formulated as

$$
V_{n}=\frac{\beta_{n}}{H_{n}} .
$$

As seen in (10), the measured voltage is inversely proportional to the liquid level. Namely, the mathematical relationship violates the linearity condition of sensors, that is, a linear relationship between the sensor output and physical quantity. Taking the logarithm of both sides of the equation leads to a linear relationship:

$$
\ln H_{n}=\ln \beta_{n}-\ln V_{n} .
$$

Now, the logarithmic wave height is proportional to the logarithmic measured voltage. Finally, water height in a linear scale is calculated as

$$
H_{n}=e^{\ln \beta_{n}-\ln V_{n}}
$$

\section{Experimental Verification}

4.1. Two-Point Wave Height Measurement for Dynamic Characterization of a TLCD. A laboratory-scaled prototype of the TLCD was fabricated with $1 \mathrm{~cm}$ thick acrylic plates (Figure 8). The width and height of the TLCD are 500 and $350 \mathrm{~mm}$, respectively. The inner dimension of vertical and 


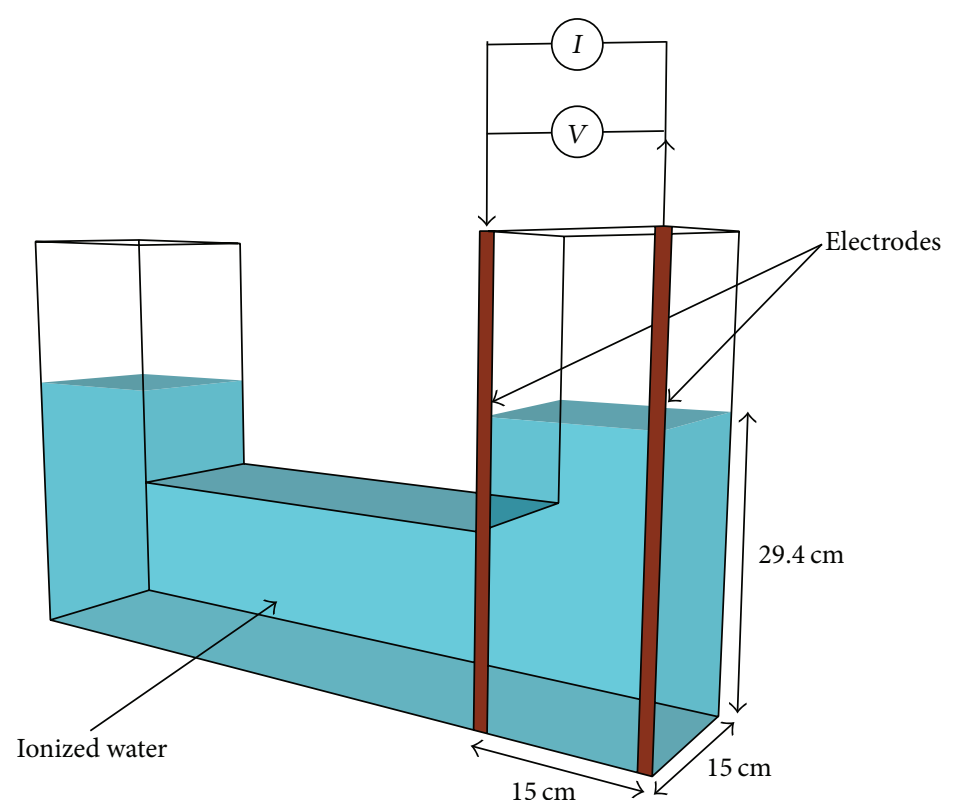

(a)

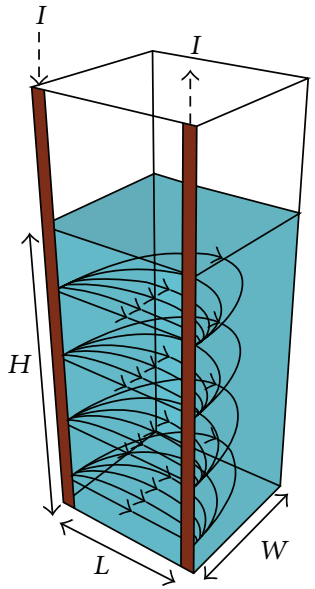

(b)

FIGURE 6: Two-point wave height measurement of a TLCD: (a) elements and dimensions; (b) current flow in liquid column.

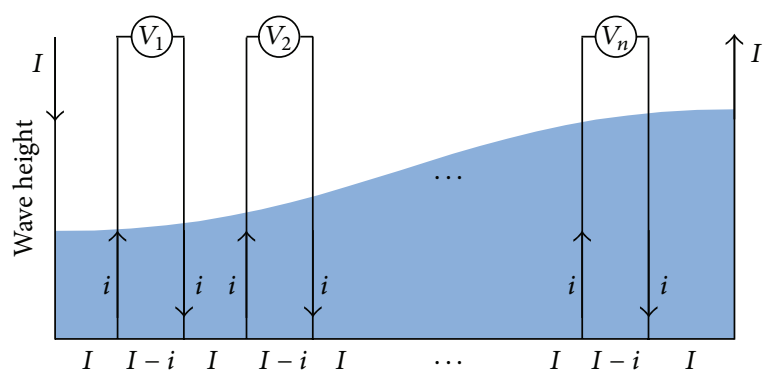

(a)

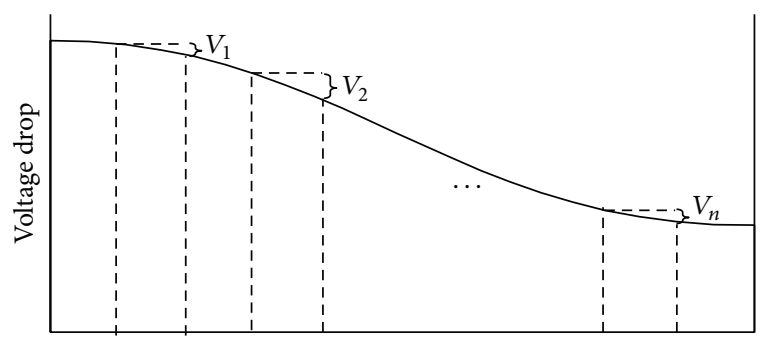

(b)

FIGURE 7: Multipoint wave height measurement of a TLD using electric field: (a) voltage sensing by various wave heights; (b) various voltage drops.

horizontal column, that is, cross-sectional area of liquid flow, is $150 \times 150 \mathrm{~mm}$. The TLCD was mounted on a uniaxial shake table driven by a mechanical linear actuator where rotary motion of an AC servo motor (HC-SFS502, MITSUBISHI) is converted to linear motion. A $60 \mathrm{sec}$ long 0.2 to $2.0 \mathrm{~Hz}$ chirp

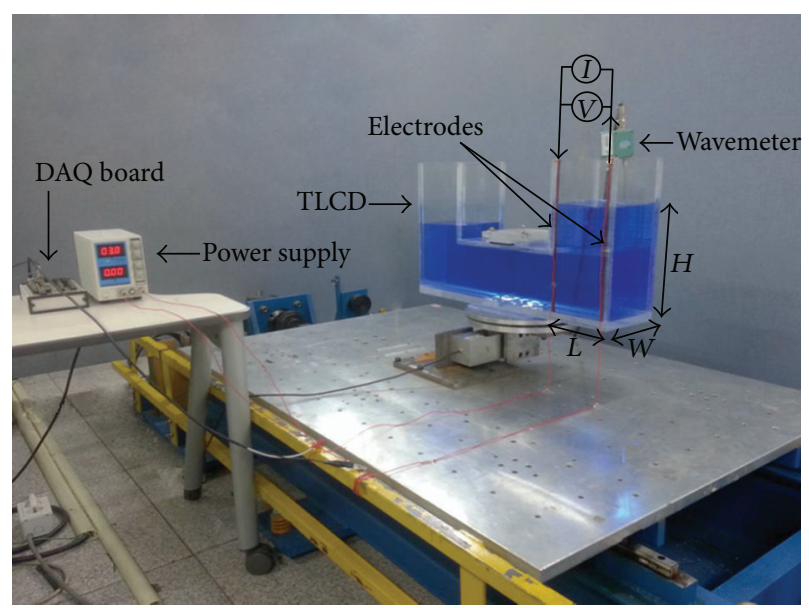

FIGURE 8: Experiment equipment of the proposed sensing of electric field.

signal with a constant amplitude of peak-to-peak $\pm 1 \mathrm{~V}$ was applied to the AC servo motor via the function generator.

Water column in the TLCD was utilized as conductive media to measure the resistance. In order to increase the conductivity of water, electrically ionized water was prepared by dissolving small amount of electrolytes into tap water. Since the specific resistance of the water was adjusted by ranging at least $100 \Omega$, the resistance value was accurately determined by the two-point method. Two copper tapes were attached on the corners of a vertical liquid column of the TLCD and connected to a DC power supplier (TDP-303A, TOYOTECH) which controlled a constant current of $0.1 \mathrm{~mA}$. 


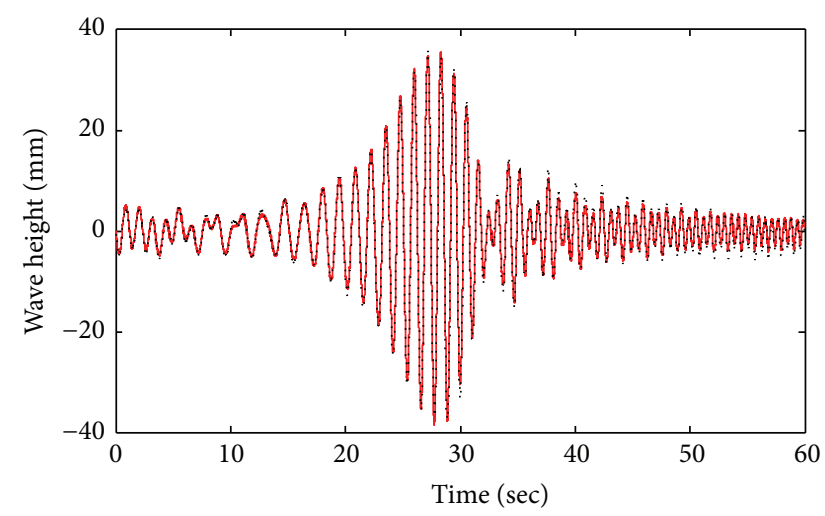

- Wave height meter Proposed

(a)

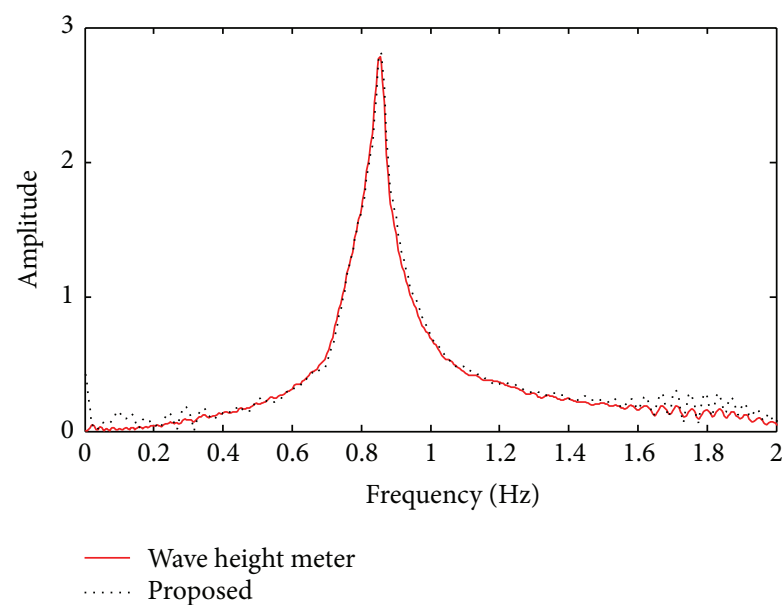

(b)

FIGURE 9: Dynamic characteristics of the TLCD: (a) measured heights; (b) corresponding Fourier spectra of the heights.

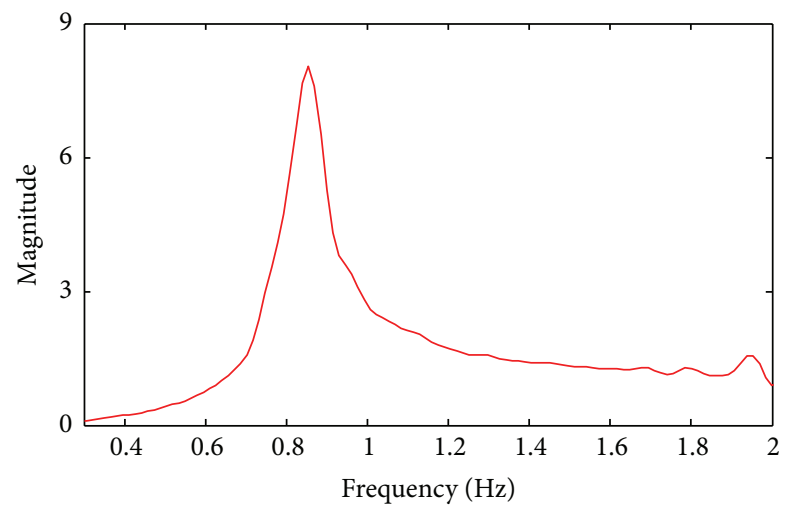

(a)

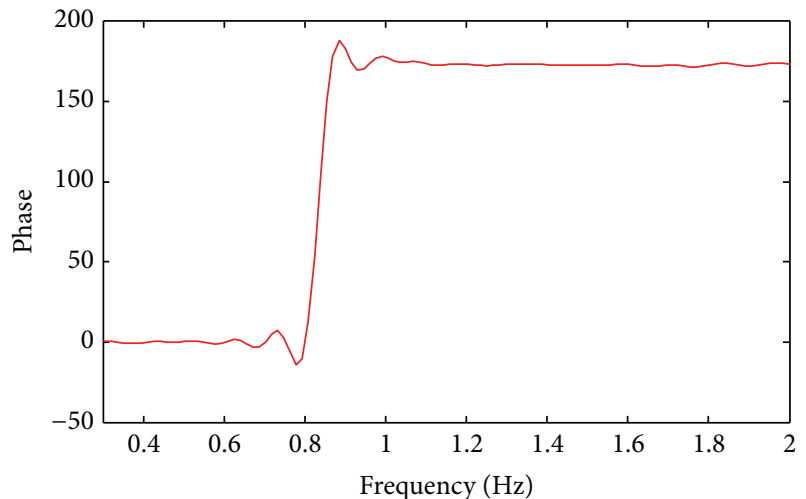

(b)

FIGURE 10: Transfer function of the TLCD: (a) magnitude; (b) phase.

A voltmeter shares the line to measure voltage drop between the electrodes. To measure and record the voltage, a DAQ system from National Instrument was interfaced with the ends of lead wires. Mapping of the measured voltage to the wave height needs determination of beta in (12). In this study, an a priori measurement of the height and voltage was conducted to determine the value.

The accuracy of voltage measurements within an electric field based wave height measurement system was crosschecked with that of a conventional wave height meter, that is, capacitive type wave height sensor (CH-601, KENEK). The wave height meter is a contact sensor; the wave probe was immersed in the liquid column of the TLCD and the sensor body was clamped on top of the TLCD as seen in Figure 8. To measure motion of the shake table, a laser displacement sensor (CD5-500, OPTEX) was utilized. During the test, each measurement system collected data for water height in the TLCD. For comparison purposes, time histories of liquid height measured by the wavemeter and proposed system are superimposed. As seen, a very close match of two measurements is observed in Figure 9(a). The RMS error between two datasets was evaluated as $1.053 \mathrm{~mm}$. The Fourier spectra of the measured liquid heights are presented in Figure 9(b). Dominant peaks at $0.85 \mathrm{~Hz}$ are clearly observed at the two measurements.

The transfer functions of the liquid height over input displacement of the shake table are estimated and then given in Figure 10. Again, a very dominant peak is found at $0.85 \mathrm{~Hz}$, being similar to the Fourier spectra. A phase delay of 180 degrees is confirmed in case of excitation of faster than $0.85 \mathrm{~Hz}$, which means opposite liquid motion against the input shake table excitation.

\subsection{Multipoint Measurement for Dynamic Characterization} of TLDs. The 4-point measurement system was deployed to identify the natural frequency and monitor sloshing in the TLD (Figure 11). A laboratory-scaled prototype of the TLD was fabricated from $1 \mathrm{~cm}$ thick acrylic plates. The length and width of the TLD are 300 and $200 \mathrm{~mm}$, respectively. The liquid is filled up to $30 \mathrm{~mm}$ in the TLD and thus length ratio $h / L$ is 0.1 . Therefore, the shallow wave theory is applicable to find 


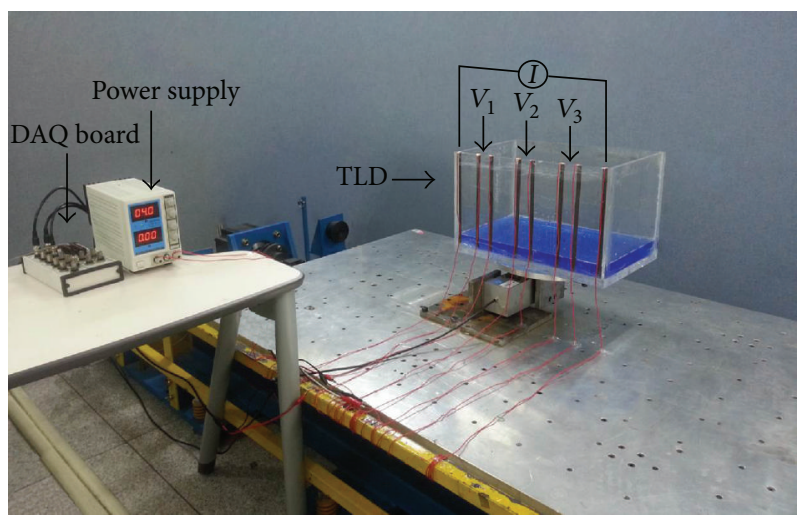

FIGURE 11: Experiment equipment of the proposed method of RTLD.

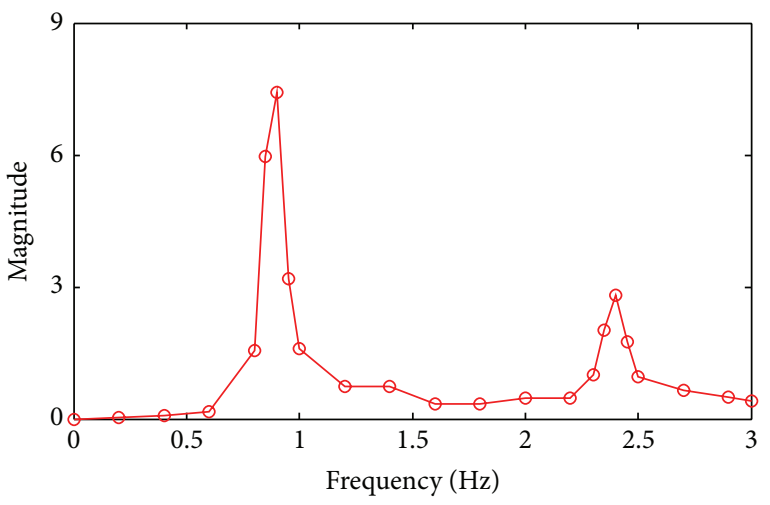

FIgURE 12: Transfer function of the TLD.

the natural frequencies of the TLD. To compose a multipoint measurement system, eight copper tapes were attached being spaced equally apart to the TLD: two tapes in both ends were used as the electrodes of the power supplier and three pairs of tapes were utilized for voltage measurements at three different points, that is, left, middle, and right.

Dynamic tests of the TLD with various frequencies of the harmonic excitation of the shake table were undertaken to verify advantages of the proposed sensing system. A total of 23 harmonic excitation tests were undertaken changing the frequencies. Since the first and second sloshing modes are estimated as 0.9 and $2.4 \mathrm{~Hz}$, respectively, from (3), excitation frequencies were adopted as $0.2,0.4,0.6,0.8,0.85,0.9,0.95$, $1,1.2,1.4,1.6,1.8,2,2.2,2.3,2.35,2.4,2.45,2.5,2.7$, and $2.9 \mathrm{~Hz}$. During the test, lateral displacement of the shake table and vertical displacement of oscillating liquid were measured and transposed into the frequency domain to estimate transfer functions. The estimated transfer functions of the liquid height at the left point over input displacement of the shake table are shown in Figure 12 where 23 circles are the experimental results. As seen in the figure, two peaks are dominantly observed at 0.9 and $2.4 \mathrm{~Hz}$ that match well the analytical frequencies from the shallow wave theory.

Sloshing motions are confirmed through investigating spatially sensed data at each natural frequency. The measured time histories of liquid motion at $0.9 \mathrm{~Hz}$ excitation are plotted

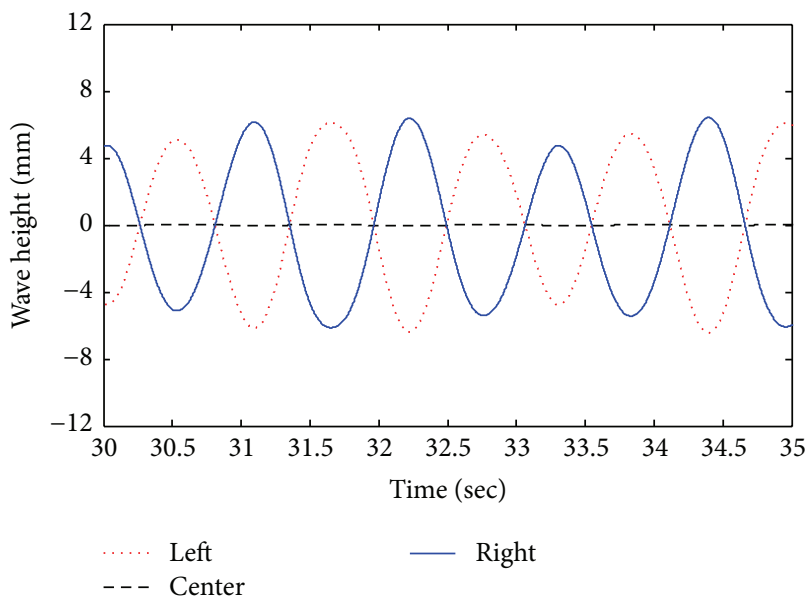

(a)

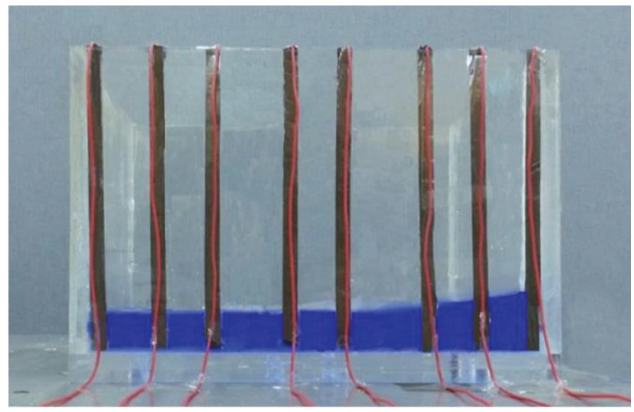

(b)

FIgURE 13: The first sloshing mode at $0.9 \mathrm{~Hz}$; (a) measured wave height; (b) wave motion.

in Figure 13(a): opposite motion is observed between the left and right points and motion at the center remains still. As a result, symmetric wave motion is captured in Figure 13(b). Figure 14 is the response of the liquid motion at $0.9 \mathrm{~Hz}$ excitation: nearly synchronous motions between the left and right points are confirmed while opposing motion at the center. Symmetric wave motion is found in Figure 14(b).

\section{Conclusions}

The liquid dampers, such as TLCD and TLD, are passive energy-absorbing devices designed to attenuate vibration of a primary structure through liquid oscillation. The liquid dampers achieve their best control performance when targeted at the harmonic motion of a primary structure. In this study, a novel wave measurement system is proposed for measurement of liquid motion in the liquid dampers. The fundamental principle of the system is based on variable voltage measurement in a constant electric field. Depending on the number of the probes submerged in the liquid, two- and four-point measurement systems are investigated: two-point measurement system is developed utilizing its simplicity. On the other hand, four-point measurement system is developed for the low resistance measurements where the two-point method yields nontrivial errors. Furthermore, the proposed 


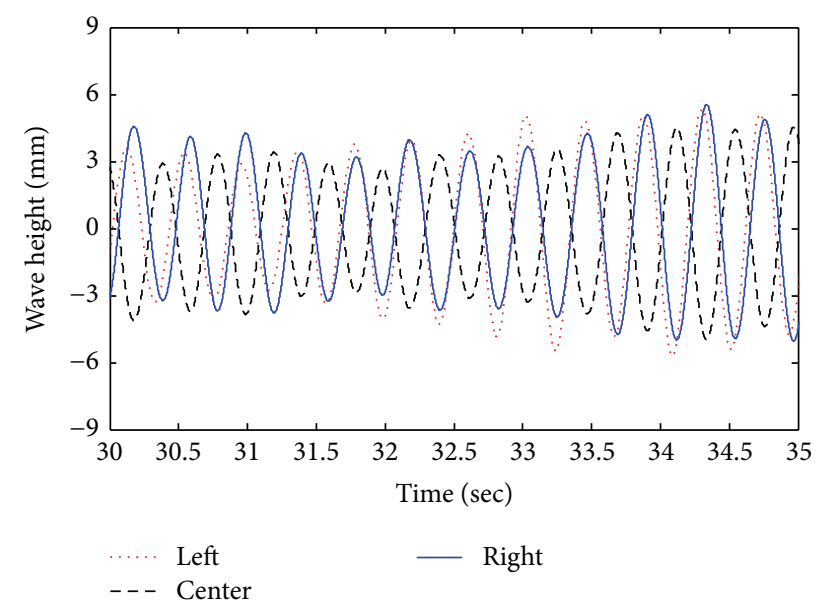

(a)

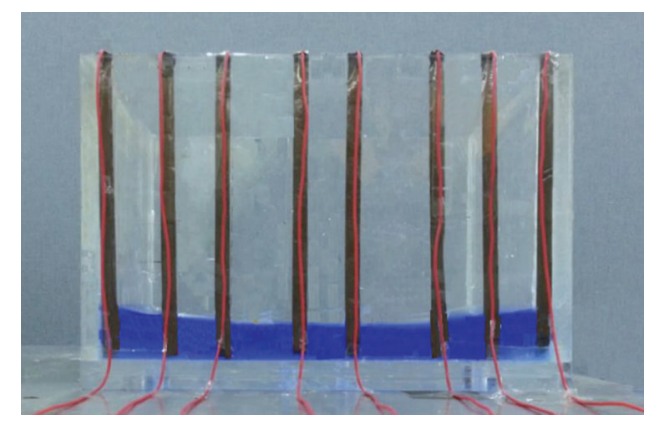

(b)

FIgURE 14: The second sloshing mode at $2.4 \mathrm{~Hz}$; (a) measured wave height; (b) wave motion.

systems can simultaneously measure the liquid height of multipoint locations in the electric field.

As for their applications to the liquid dampers, twopoint wave height measurement is deployed for dynamic characterization of the TLCD and multipoint measurement is developed for the TLD. In laboratory tests with a prototype of the TLCD, accuracy of the proposed system is confirmed through comparison with a conventional wavemeter and natural frequency is successfully evaluated. In addition, multipoint wave height measurement is performed with laboratory tests with a prototype of the TLD and various sloshing modes of the TLD are observed. As a result, costeffectiveness and multipoints are demonstrated.

\section{Competing Interests}

The authors declare that there is no conflict of interests regarding the publication of this paper.

\section{Acknowledgments}

This work is supported by the Basic Research Programs (NRF-2015R1C1A1A01054155, NRF-2015R1D1A1A01060643) of the National Research Foundation (NRF) of Korea funded by Ministry of Education, Science and Technology (MEST).

\section{References}

[1] A. Kareem, T. Kijewski, and Y. Tamura, "Mitigation of motions of tall buildings with specific examples of recent applications," Wind and Structures, vol. 2, no. 3, pp. 201-251, 1999.

[2] J. P. Den Hartog, Mechanical Vibrations, McGraw-Hill, New York, NY, USA, 4th edition, 1956.

[3] Y. Fujino, L. Sun, B. M. Pacheco, and P. Chaiseri, "Tuned liquid damper (TLD) for suppressing horizontal motion of structures," Journal of Engineering Mechanics, vol. 118, no. 10, pp. 2017-2030, 1992.

[4] L. M. Sun, Y. Fujino, B. M. Pacheco, and P. Chaiseri, "Modelling of tuned liquid damper (TLD)," Journal of Wind Engineering and Industrial Aerodynamics, vol. 43, no. 1-3, pp. 1883-1894, 1992.

[5] K. C. S. Kwok and B. Samali, "Performance of tuned mass dampers under wind loads," Engineering Structures, vol. 17, no. 9, pp. 655-667, 1995.

[6] K.-W. Min, J. Kim, and Y.-W. Kim, "Design and test of tuned liquid mass dampers for attenuation of the wind responses of a full scale building," Smart Materials and Structures, vol. 23, no. 4, Article ID 045020, 2014.

[7] Y. Tamura, K. Fujii, T. Ohtsuki, T. Wakahara, and R. Kohsaka, "Effectiveness of tuned liquid dampers under wind excitation," Engineering Structures, vol. 17, no. 9, pp. 609-621, 1995.

[8] P. Benerfi, M. Murudi, and A. H. Shah, "Tuned liquid dampers for controlling earthquake response of structures," Earthquake Engineering and Structural Dynamics, vol. 29, pp. 454-463, 2000.

[9] K.-W. Min, J. Kim, and H.-R. Lee, "A design procedure of twoway liquid dampers for attenuation of wind-induced responses of tall buildings," Journal of Wind Engineering and Industrial Aerodynamics, vol. 129, pp. 22-30, 2014.

[10] F. Sakai, S. Takaeda, and T. Tamaki, "Tunes liquid column damper-new type device for suppression of building vibration," in Proceedings of the International Conference on High-Rise Building, pp. 926-931, Nanjing, China, 1989.

[11] Y. L. Xu, B. Samali, and K. C. S. Kwok, "Control of alongwind response of structures by mass and liquid dampers," ASCE Journal of Engineering Mechanics, vol. 118, no. 1, pp. 20-39, 1992.

[12] J.-K. Yu, T. Wakahara, and D. A. Reed, "A non-linear numerical model of the tuned liquid damper," Earthquake Engineering and Structural Dynamics, vol. 28, no. 6, pp. 671-686, 1999.

[13] H. Gao, K. C. S. Kwok, and B. Samali, "Optimization of tuned liquid column dampers," Engineering Structures, vol. 19, no. 6, pp. 476-486, 1997.

[14] S. K. Yalla and A. Kareem, "Optimum absorber parameters for tuned liquid column dampers," Journal of Structural Engineering, vol. 126, no. 8, pp. 906-915, 2000.

[15] J.-C. Wu, C.-H. Chang, and Y.-Y. Lin, "Optimal designs for nonuniform tuned liquid column dampers in horizontal motion," Journal of Sound and Vibration, vol. 326, no. 1-2, pp. 104-122, 2009.

[16] F. Ziegler, “The tuned liquid column damper as a cost-effective alternative for the mechanical damper in civil engineering structures," International Journal of Acoustics \& Vibrations, vol. 12, no. 1, pp. 25-39, 2007.

[17] J.-C. Wu, M.-H. Shih, Y.-Y. Lin, and Y.-C. Shen, "Design guidelines for tuned liquid column damper for structures responding to wind," Engineering Structures, vol. 27, no. 13, pp. 1893-1905, 2005. 
[18] C. C. Chang and W. L. Qu, "Unified dynamic absorber design formulas for wind-induced vibration control of tall buildings," The Structural Design of Tall Buildings, vol. 7, no. 2, pp. 147-166, 1998.

[19] F. Ziegler, "Special design of tuned liquid column-gas dampers for the control of spatial structural vibrations," Acta Mechanica, vol. 201, no. 1-4, pp. 249-267, 2008.

[20] Y. Fujino, L. Sun, B. M. Pacheco, and M. Isobe, "Nonlinear waves and dynamic pressure in rectangular tuned liquid damper (TLD): simulation and experimental verification," Structural Engineering/Earthquake Engineering, JSCE, vol. 6, no. 2, pp. 8192, 1989.

[21] K. Schroder, Semiconductor Material and Device Characterization, John Wiley and Sons, 2nd edition, 1998.

[22] F. M. Smits, "Measurement of sheet resistivities with the fourpoint probe," Bell System Technical Journal, vol. 37, no. 3, pp. 711$718,1958$.

[23] F. Wenner, "A method of measuring earth resistivity," Bulletin of the Bureau of Standards, vol. 12, no. 4, pp. 469-478, 1915.

[24] L. B. Valdes, "Resistivity measurements on germanium for transistors," Proceedings of the IRE, vol. 42, no. 2, pp. 420-427, 1954.

[25] R. Hall, "Minimizing errors of four point probe measurements on circular wafers," Journal of Scientific Instruments, vol. 44, no. 1, pp. 53-54, 1967. 


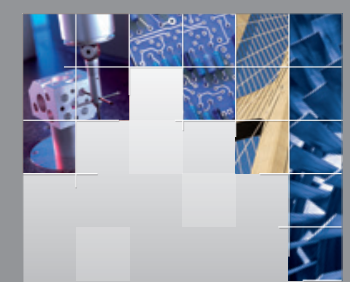

\section{Enfincering}
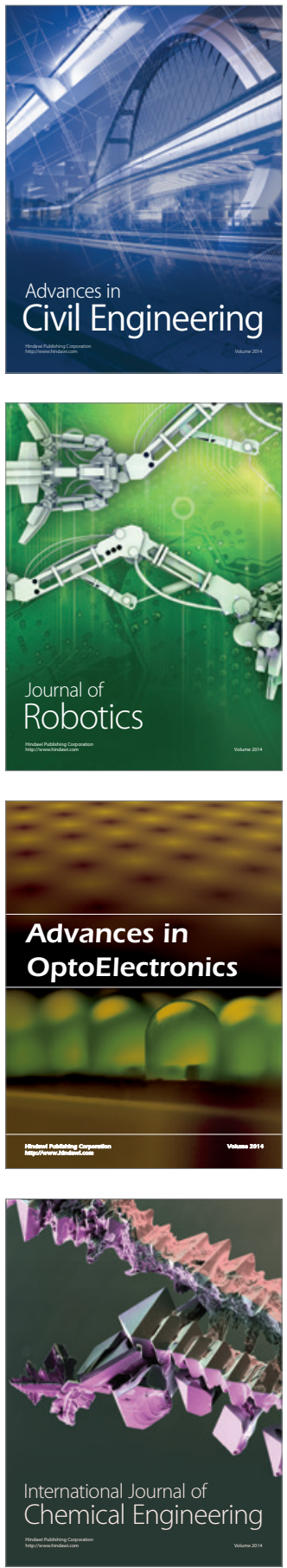

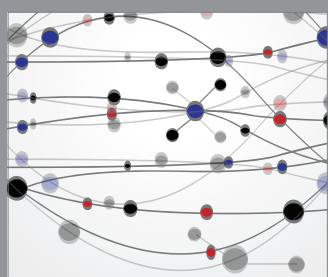

The Scientific World Journal

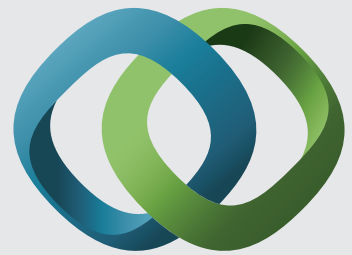

\section{Hindawi}

Submit your manuscripts at

http://www.hindawi.com
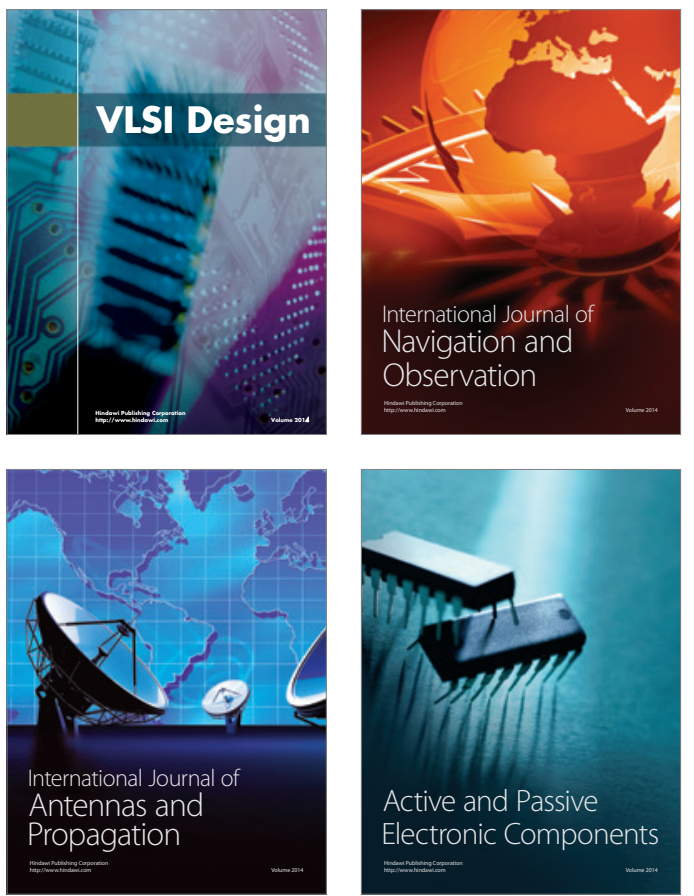
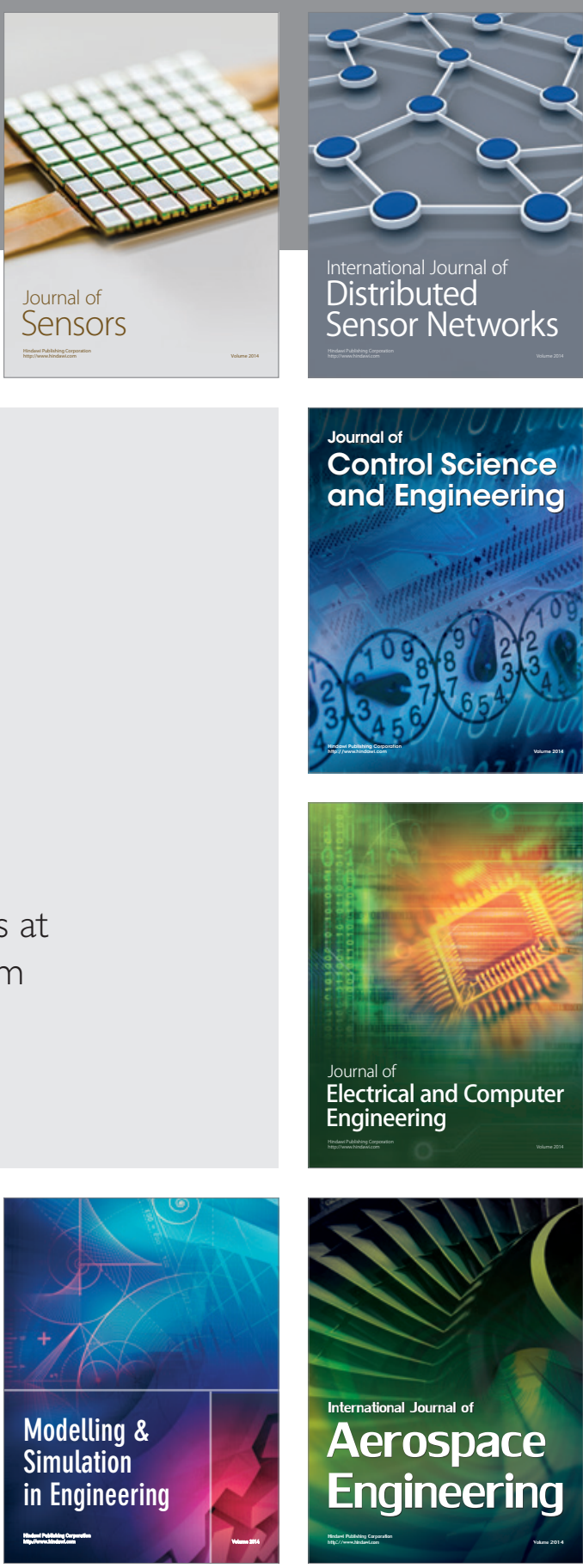

International Journal of

Distributed

Sensor Networks

Journal of

Control Science

and Engineering
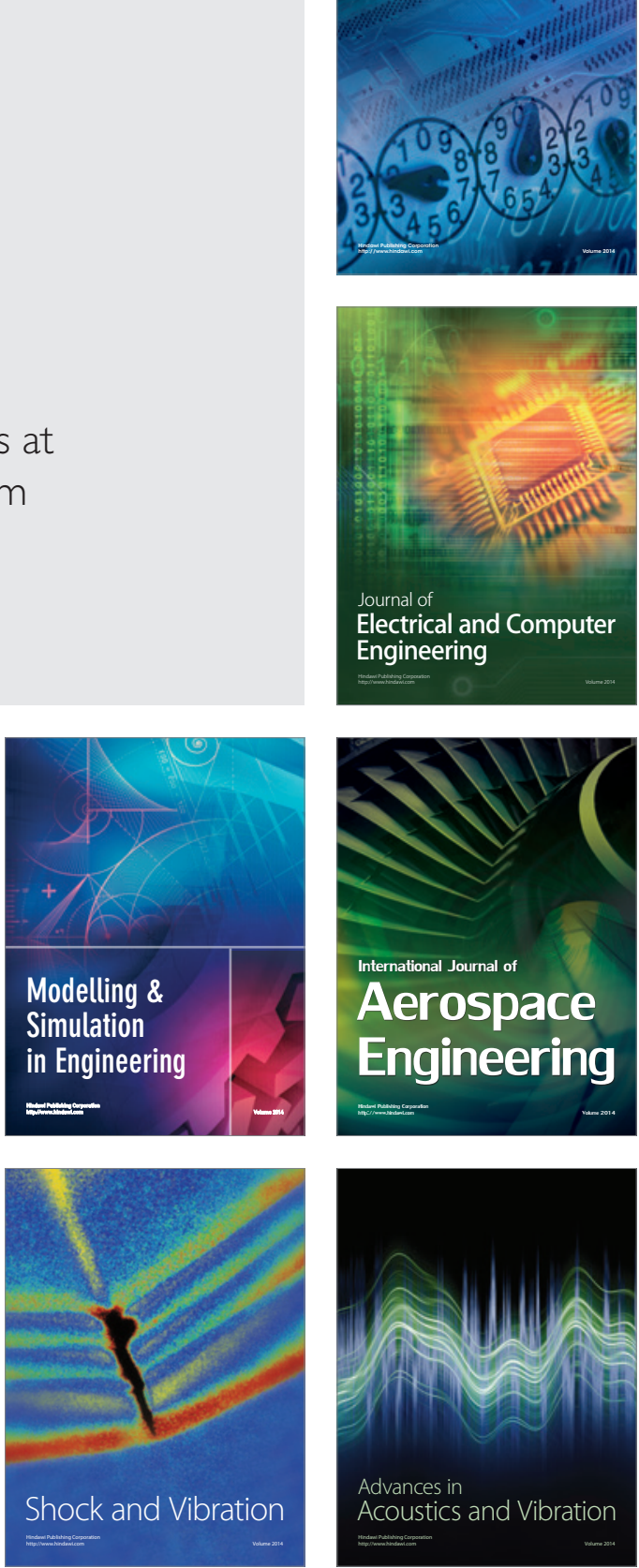